\title{
A case of Langerhans cell histiocytosis mimicking child abuse
}

\author{
Şakire Başer ${ }^{1}$, Ayşe Kaman², Işıl Zaimoğlu'1, Zeynep Gökçe Gayretli-Aydın², Türkan \\ Aydın-Teke ${ }^{2}$, Umut Kaygusuz ${ }^{3}$, Asuman Gürkan ${ }^{4}$, Esin Boduroğlu ${ }^{5}$, Yasemin TaşC1 ${ }^{6}$, \\ Gönül Tanır ${ }^{2}$ \\ ${ }^{2}$ Division of Pediatric Infectious Diseases, Departments of ${ }^{1}$ Pediatrics, ${ }^{3}$ Ear, Nose and Throat Diseases, ${ }^{4}$ Dermatology, \\ ${ }^{5}$ Pathology, ${ }^{6}$ Radiology, Dr Sami Ulus Maternity and Children's Training and Research Hospital, Ankara, Turkey. \\ E-mail: sakirebaser@gmail.com \\ Received: 2nd May 2016, Revised: 11th July 2016, Accepted: 17th August 2016
}

SUMMARY: Başer Ş, Kaman A, Zaimoğlu I, Gayretli-Aydın ZG, Aydın-Teke T,
Kaygusuz U, Gürkan A, Boduroğlu E, Taşcı Y, Tanır G. A case of Langerhans
cell histiocytosis mimicking child abuse. Turk J Pediatr 2016; 58: 675-678.
Langerhans cell histiocytosis is a rare non-malignant disease with clinical
heterogeneity. The disease may present with various clinical findings and
may imitate many other conditions. In this report we describe a 34-month-
old girl who presented with chronic otitis and otorrhea, skull fracture, rash,
vulvar edema, erythema and erosion in labia majors which initially suggested
child abuse but the patient was diagnosed with Langerhans cell histiocytosis.

Key words: Langerhans cell histiocytosis, child abuse.

Langerhans cell histiocytosis ( $\mathrm{LCH})$ is a myeloid cell-based neoplasm characterized by the reactive clonal increase of Langerhans cells and consisting of the components of autoimmune inflammatory disease ${ }^{1}$. Moreover, this disease is genetically related to BRAF-V600E gene mutation influencing the MAPK signaling pathway. Incidence rate is $8.9 /$ million per year among children under the age of fifteen 2 . Potential symptoms encountered in $\mathrm{LCH}$ diagnosis in adults and children may also be observed in numerous diseases. Differential diagnosis is based on the presentation of typical histopathological findings or CD1a positive cells ${ }^{3}$.

Tissue damage that was caused by someone else due to any reason is defined as physical abuse ${ }^{4}$. The awareness of conditions that simulate child abuse enables the ability to diagnose correctly. We presented a case of $\mathrm{LCH}$ mimicking child abuse in this report.

\section{Case Report}

A 34-month-old girl was admitted to hospital with fever, rash, ear discharge and vaginal secretion. Medical history revealed crusted rash on the scalp and intertriginous areas and ear drainage from six months of age. Systemic and topical antibiotic treatments were prescribed several times with the diagnosis of acute otitis media and seborrheic dermatitis in other hospitals. At the age of one, laser polypectomy was performed through both of the external auditory canals. In addition to these complaints, vaginal secretion was observed for the last five months, and fever and rash were noted for the last five days. The patient, whose parents were third-degree relatives, had a one-year-old healthy sister.

On physical examination, her general condition was moderate and she was apparently agitated. Remaining data about her physical examination were as follows; body temperature $38.1{ }^{\circ} \mathrm{C}$, respiratory rate $24 / \mathrm{min}$, pulse $101 / \mathrm{min}$, arterial blood pressure 100/60 mm Hg. Apparent and locally yellowish clotted plaque was seen on the scalp, and broad erythematous skin was observed beneath it. Petechial-purpuric rashes were seen on the whole trunk and extremities. Bilateral external auditory canal was obliterated with polypoid lesion and purulent discharge. Purulent discharge, vulvar edema, erythema in labia majors, and local erosion were detected on intertriginous areas on the examination of genitourinary system. Other system examinations were normal.

Routine laboratory investigations were as follows; hemoglobin ( $\mathrm{Hb}) 8.9 \mathrm{gr} / \mathrm{dl}$, white 


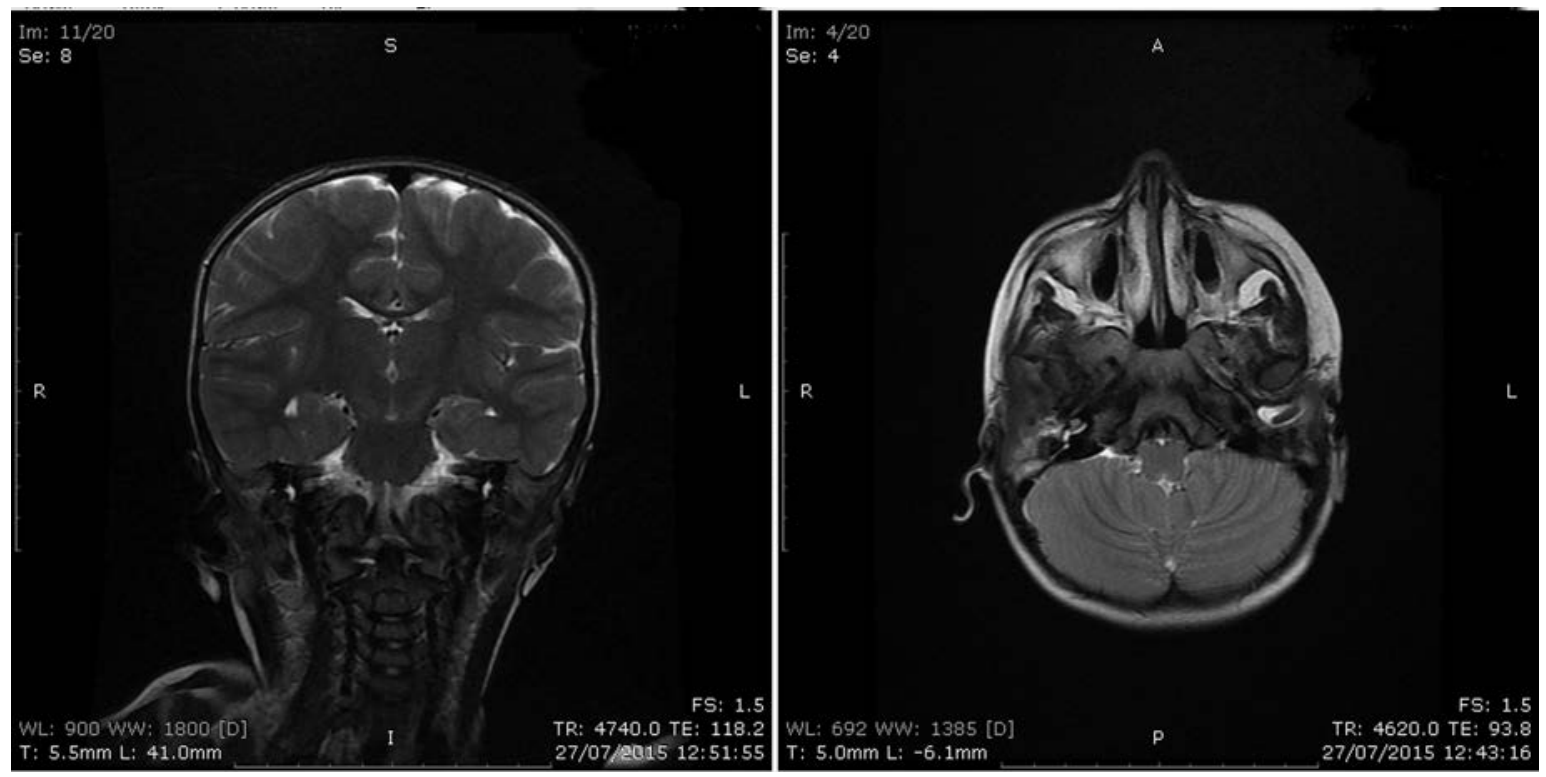

Fig. 1. Coronal T2 weighted image also demonstrates destruction of the tegmen tympani with minimal soft tissue extension to the middle cranial fossa (left). Axial and coronal T2 weighted MR images reveal fluid and soft tissue filling the mastoid air cells bilaterally, greater on the right. The soft tissue extends to the tympanic cavity bilaterally and to the subcutaneous tissue on the left. The integrity of temporal bones and the borders of the mass lesion could not be determined (right).

blood cell count (WBC) $14,900 / \mathrm{mm}^{3}(60 \%$ neutrophil, $30 \%$ lymphocyte, $8 \%$ monocyte, $\% 2$ eosinophil), platelet count $661,000 / \mathrm{mm}^{3}$, C-reactive protein (CRP) $174 \mathrm{mg} / \mathrm{dl}(0-4 \mathrm{mg} /$ $\mathrm{dl}$ ), erythrocyte sedimentation rate (ESR) 71 $\mathrm{mm} / \mathrm{h}$, aspartate aminotransferase (AST) 15 $\mathrm{U} / \mathrm{L}(<48 \mathrm{U} / \mathrm{L})$, alanine aminotransferase (ALT) $73 \mathrm{U} / \mathrm{L}$ (0-56 U/L), and gamma-glutamyl transpeptidase (GGT) $261 \mathrm{U} / \mathrm{L}(<23 \mathrm{U} / \mathrm{L})$. Other biochemical evaluations and coagulation tests were normal. Urinalysis revealed plenty of leukocyte and urine leukocyte esterase strip were $3(+)$. Cerebrospinal fluid (CSF) examination was normal. Serologic tests for human immunodeficiency virus (HIV), EbsteinBarr virus (EBV), cytomegalovirus (CMV) and syphilis were all negative, and serum quantitative immunoglobulin levels were normal according to her age.

Ceftriaxone was empirically commenced for the suspicions of urinary tract infection and chronic vulvitis. Cultures of blood and CSF were resulted as negative. Temporal computed tomography (CT) scan revealed numerous fractures in right temporal and bilateral mastoid bone. Cranial CT was performed due to suspicion of child abuse and no cerebral hemorrhage or contusion were revealed. Abdominal ultrasonography(USG) showed heterogeneity of liver and these findings were interpreted as a lesion that might develop depending on contusion, infiltrative disease or infectious process. Whole body direct bone survey graphics were normal.

A diagnosis of physical child abuse was suspected because of the bilateral fracture in temporal CT, the abdomen USG image that compatible with the liver contusion and purulent genital discharge, vulvar edema, erythema in labia majors and the local erosion that was detected on the examination of genitourinary system. Further social history of family was questioned by social workers.

Contrast-enhanced temporal magnetic resonance imaging (MRI) revealed soft tissue intensities in both of the squamous and mastoid parts of temporal bone, surrounding the external auditory canal and extending to the tympanic cavity. Diffuse contrasting was observed in the meningeal structures at the levels of both temporal lobes (Fig. $1)$. Histiocytosis $X$ was firstly considered in the differential diagnosis. Histopathological analysis of the biopsy specimen taken from the lesions on the scalp and axillary area demonstrated an infiltration developing in a way of filling the upper dermis under the epidermis, having the diffuse developmental 


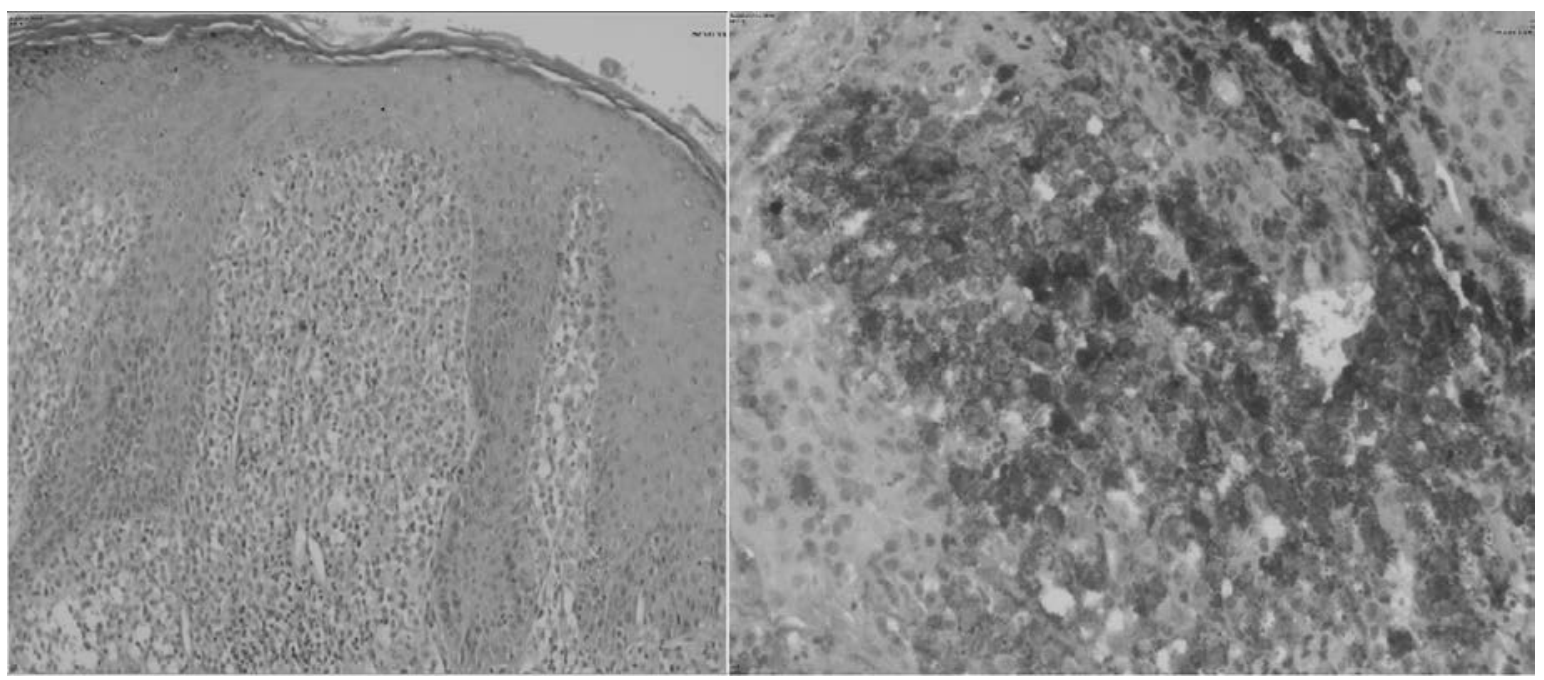

Fig. 2. Diffuse growth of the tumor filling the upper dermis HEx100 (left). CD1a and S-100, that they were locally positive with CD34, and adjacent cells were stained with CD68 strong positive staining cytoplasm of neoplastic cells, CD1a,x200 (right).

pattern that extending to the lower dermis, and consisting of atypical cells with big vesicular anisocoric nucleus, small nucleolus, and large eosinophilic cytoplasm(Fig. 2). Giant cell formation was not recorded. The patient was diagnosed as $\mathrm{LCH}$ according to these findings. In the bone scintigraphy taken for staging the disease, focally increased activity involvement was recorded on the area complying with the adjacency of left temporal bone-sphenoid bone, and the distribution of activities was measured to be at the desired level and symmetry in the lines of epiphysis and for other bones in the body. Bone marrow aspiration revealed no involvement. The treatment protocol with vinblastine and prednisone was administered to the patient. She has been on follow-up for eight months uneventfully, her MRI findings returned to normal.

\section{Discussion}

Langerhans cell histiocytosis has been defined as a heterogeneous clinical condition occurring with the clonal proliferation of bone marrow-based dendritic cells of the epidermis ${ }^{5}$. The disease may involve any organ or tissue. Although the involvements of skeletal system and skin are the most commonly seen, parenchymal organs, lymph nodes, and central nervous system may also be involved ${ }^{6}$. Nowadays, $\mathrm{LCH}$ classification is made by taking into account the number of affected areas (single or multi-systemic and local or multifocal) and involvement of the risk organs. Bone marrow, liver, and spleen involvement are considered as high stage disease $^{2}$. Ear involvement and rash related to the skin involvements that are commonly seen in this disease were present in our patient whose complaints started when she was six months old. The patient was evaluated as having systemic form as expected for that age group. The involvement of eyes and endocrine system which may be observed in the systemic form was not present in our patient. Similar to this case, the cases with chronic otitis and otorrhea depending on the temporal bone were reported, previously ${ }^{7,8}$.

Although the physical examination findings are numerous in child abuse, ecchymosis, bite marks, fractures, injuries in internal organs, and head trauma are the most commonly reported findings ${ }^{9}$. Skull fractures may be present due to accidents as well as the child abuse. Especially more than one complicated skull fracture and compression fractures are the indications increasing the probability of child abuse ${ }^{10}$. In the present case, child abuse was included in the differential diagnosis due to the bilateral fracture in temporal $\mathrm{CT}$ and the ultrasonographic images that were compatible with the liver contusion. A study that included 25 pediatric $\mathrm{LCH}$ patients reported that, $\mathrm{LCH}$ imaging findings are not specific, they might be similar to the infection, inflammation or neoplastic diseases, and they might even imitate 
the traumas not related to accidents ${ }^{11}$.

Skin findings of LCH may also vary to some extent. The differential diagnosis should include especially seborrheic dermatitis, psoriasis, atopic dermatitis and scabies. Acrodermatitis enteropathica, 'blueberry muffin' type rash, and molluscum contagiosum were reported as the findings that might be rarely confused with $\mathrm{LCH}$ 12-14. Recurrent skin findings of our patient had been evaluated as seborrheic dermatitis, and the treatment was administered according to this diagnosis. Petechial rash is a rare symptom seen in $\mathrm{LCH}{ }^{13}$. In this case, the probability of child abuse was considered due to the presence of distinct vulvar, labial edema and laceration, her unfavorable general hygienic condition, and the detection of the images compatible with fracture and contusion. Since the detection of vulvar lesions in the age group of children is a highly stimulant factor in terms of child abuse, professional social service evaluation was made. It was reported that, a 4-year-old patient with bilateral vulvar vesicular lesions and surrounding erythema, who developed diabetes insipidus during the follow-up, was diagnosed as vulvar LCH with central nervous system involvement ${ }^{15}$.

Langerhans cell histiocytosis is diagnosed through the clinical, radiological findings and histological and immunophenotyping analysis of the biopsy taken from the lesion or involved organ if any in systemic involvement ${ }^{16}$. The present case had temporal MRI findings compatible with histiocytosis $\mathrm{X}$, bilateral external auditory canal obliteration, hepatic, vulvar and skin involvement. For this reason, systemic form of $\mathrm{LCH}$ was considered and diagnosis was confirmed by means of typical histopathological findings on biopsy.

When the cases of child abuse are early noticed, the abused children can be saved from chronic abuse or death. For this reason, detailed medical history and analyses of physical examination findings are quite significant for the early diagnosis of child abuse. LCH may present with various clinical findings and may imitate many other conditions. LCH should be considered in cases of chronic otitis and otorrhea that are resistant to the medical treatment, and ear involvement may result with formation of polyps and also the disease should be kept in mind in young children who had complaints similar to the findings of child abuse.

\section{REFERENCES}

1. Zinn DJ, Chakraborty R, Allen CE. Langerhans Cell Histiocytosis: Emerging Insights and Clinical Implications. Oncology (Wiliston Park) 2016; 30: 122-132.

2. Lee JW, Shin HY, Kang HJ, et al. Clinical characteristics and treatment outcome of Langerhans cell histiocytosis: 22 years' experience of 154 patients at a single center. Pediatr Hematol Oncol 2014; 31: 293-302.

3. Monsereenusorn C, Rodriguez-Galindo C. Clinical Characteristics and Treatment of Langerhans Cell Histiocytosis. Hematol Oncol Clin North Am 2015; 29: 853-873.

4. Beyaztaş YF, Oral R, Butun C, Beyaztaş A, Buyukkayhan D. Fiziksel cocuk istismarı: Dört vakanın sunumu. Cocuk Sağlığı ve Hastalıkları Dergisi 2009; 52: 75-80.

5. Hussein MR. Skin-limited Langerhans' cell histiocytosis in children. Cancer Invest 2009; 27: 504-511.

6. Weitzman S, Egeler M. Histiocytic disorders of children and adults: introduction to the problem, overview, historical perspective and epidemiology. In: Weitzman S, Egeler M (eds). Hisitiocytic Disorders of Children and Adults (1 ${ }^{\text {st }}$ ed). Cambridge: W.B. Saunders, 2005; $1-13$.

7. Kleinjung $\mathrm{T}$, Woenckhaus $\mathrm{M}$, Bachthaler $\mathrm{M}$, et al Langerhans' cell histiocytosis with bilateral temporal bone involvement. Am J Otolaryngol 2003; 24: 265270.

8. Postovsky S, Daitzchman M, Dale A, et al. Unusual presentation of mastoid eosinophilic granuloma in a young patient. Pediatr Hematol Oncol 2001; 18: 283289.

9. Koc F, Halıcıoğlu O, Akşit S. Which findings may suggest physical abuse? J Pediatr Res 2014; 1: 1-5.

10. Hobbs CJ. Skull fracture and the diagnosis of abuse. Arch Dis Child 1984; 59: 246-252.

11. Fitzgerald NE, MacClain KL. Imaging characteristics of hemophagocytic lymphohistiocytosis. Pediatr Radiol 2003; 33: 392-401.

12. Huang JT, Mantagos J, Kapoor R, Schmidt B, Maguiness S. Langerhans cell histiocytosis mimicking molluscum contagiosum. J Am Acad Dermatol 2012; 67:117-118.

13. Shaffer MP, Walling HW, Stone MS. Langerhans cell histiocytosis presenting as blueberry muffin baby. J Am Acad Dermatol 2005; 53: 143-146.

14. Papa CA, Pride HB, Tyler WB, Turkewitz D. Langerhans cell histiocytosis mimicking child abuse. J Am Acad Dermatol 1997; 37: 1002-1004.

15. Roche E, Pandya N, Munthali L, Atra A. Genital ulceration in a 4 year old-- a case of safeguarding? From social services to pathology. BMJ Case Rep 2012; 21: 2012.

16. Donadieu J, Chalard F, Jeziorski E. Medical management of langerhans cell histiocytosis from diagnosis to treatment. Expert Opin Pharmacother 2012; 13: 13091322. 